\title{
Welfare-enhancing hard core cartels
}

Citation for published version (APA):

Bos, A. M., \& Pot, E. A. (2010). Welfare-enhancing hard core cartels. METEOR, Maastricht University School of Business and Economics. METEOR Research Memorandum No. 004 https://doi.org/10.26481/umamet.2010004

Document status and date:

Published: 01/01/2010

DOI:

10.26481/umamet.2010004

Document Version:

Publisher's PDF, also known as Version of record

\section{Please check the document version of this publication:}

- A submitted manuscript is the version of the article upon submission and before peer-review. There can be important differences between the submitted version and the official published version of record.

People interested in the research are advised to contact the author for the final version of the publication, or visit the DOI to the publisher's website.

- The final author version and the galley proof are versions of the publication after peer review.

- The final published version features the final layout of the paper including the volume, issue and page numbers.

Link to publication

\footnotetext{
General rights rights.

- You may freely distribute the URL identifying the publication in the public portal. please follow below link for the End User Agreement:

www.umlib.nl/taverne-license

Take down policy

If you believe that this document breaches copyright please contact us at:

repository@maastrichtuniversity.nl

providing details and we will investigate your claim.
}

Copyright and moral rights for the publications made accessible in the public portal are retained by the authors and/or other copyright owners and it is a condition of accessing publications that users recognise and abide by the legal requirements associated with these

- Users may download and print one copy of any publication from the public portal for the purpose of private study or research.

- You may not further distribute the material or use it for any profit-making activity or commercial gain

If the publication is distributed under the terms of Article $25 \mathrm{fa}$ of the Dutch Copyright Act, indicated by the "Taverne" license above, 


\section{Maastricht University}

I wan Bos, Erik Pot

Welfare-Enhancing Hard Core Cartels

$\mathrm{RM} / 10 / 004$

\section{METEOR}

Maastricht University School of Business and Economics

Maastricht Research School of Economics

of Technology and Organization

P.O. Box 616

NL - 6200 MD Maastricht

The Netherlands 


\title{
Welfare-Enhancing Hard Core Cartels*
}

\author{
Iwan $\operatorname{Bos}^{\dagger}$ \\ Department of Organization \& Strategy \\ Maastricht University School of Business and Economics \\ Erik Pot \\ Department of Quantitative Economics \\ Maastricht University School of Business and Economics
}

February 10, 2010

JEL Classification: L1, L4

Key Words: Antitrust, Cartels, Welfare-Enhancing Collusion

\begin{abstract}
The conventional wisdom is that cartels are bad. In particular, cartels that merely lead to lower production levels and higher prices are thought to be exclusively detrimental to social welfare. This is reflected in the fact that most capitalist societies have declared such so-called hard core cartel arrangements illegal per se. In this paper, we question this rather rigid approach to hard core cartels. In a simple but fairly general setting, we provide necessary and sufficient conditions for the existence of a hard core cartel that is beneficial for firms and society at large. We consider both strong (with side payments) and weak (without side payments) hard core cartel contracts and find that $(i)$ both strong and weak welfare-enhancing cartels exist when at least one firm makes a loss on part of its sales in competition, (ii) a welfare-enhancing strong cartel exists whenever there is a difference in unit costs at competitive production levels, and (iii) a welfare-enhancing weak cartel exists when this difference is sufficiently large.
\end{abstract}

${ }^{*}$ We are indebted to Ronald Peeters and Dries Vermeulen for helpful comments. All opinions and errors are ours alone.

${ }^{\dagger}$ Corresponding author at: Tongersestraat 53, 6211 LM, Maastricht, The Netherlands. Phone: +31 (0)43-388-2626. Fax: +31 (0)43-388-4893. E-mail: i.bos@maastrichtuniversity.nl. 


\section{Introduction}

Standard economic theory teaches that cartels are detrimental to social welfare. Firms engaging in a cartel generally limit production and raise prices, which results in allocative inefficiencies and additionally leads to a redistribution of income from consumers to producers. Compared to a competitive market, some customers refrain from purchasing (or buy less-preferred substitutes), while others have to spend a larger portion of their budget to obtain the product or service. In addition, cartels are believed to give rise to technical and $\mathrm{X}$-inefficiencies. In absence of competition, firms are thought to lack incentives to organize their operations and production as efficient as possible. ${ }^{1}$ As the conventional wisdom is that cartels have no obvious benefits for society, most capitalist societies have adopted antitrust laws declaring cartel contracts illegal. In particular, the antitrust system typically does not allow for an assessment of the costs and benefits of a cartel arrangement to determine its (il)legality and proving its existence often suffices to establish an infringement of the antitrust laws.

In this paper, we question this rather rigid approach to cartels. We do so by showing that, under certain conditions, cartels can lead to an increase of social welfare. Our approach to welfare is 'neutral' in the sense that we define it as the sum of consumer and producer surplus. ${ }^{2}$ We restrict ourselves to horizontal cartels that have a direct impact on market prices. ${ }^{3}$ In practice, such so-called hard core cartels can take a variety of forms. ${ }^{4}$ The Organization for Economic Co-operation and Development (OECD) defines a hard core cartel as "an anticompetitive agreement, anticompetitive concerted practice, or anticompetitive arrangement by competitors to fix prices, make rigged bids (collusive tenders), establish output restrictions or quotas, or share or divide markets by allocating customers, suppliers, territories, or lines of commerce." 5 In our analysis, we focus on hard core cartel contracts that lead exclusively to a decrease of industry output and higher prices. We consider two types of hard core cartel contracts; one with and one without side payments. In a simple but fairly general framework, we provide necessary and sufficient conditions for the existence of a hard core cartel that is beneficial for firms and society at large.

Welfare-enhancing cartels with side payments (strong cartels) and without side payments (weak cartels) both exist when price is below unit costs at competitive production levels for at least one firm, i.e., when at least one firm makes a loss on part

\footnotetext{
${ }^{1}$ One could further think of inefficiencies that arise because firms may spend part of their resources to establish and maintain the cartel and to protect its market power.

${ }^{2}$ In Section 5, we discuss to what extent our analysis is robust against alternative notions of social welfare, e.g., consumer surplus instead of total surplus.

${ }^{3}$ Some horizontal cartels only affect the price mechanism indirectly. See, for example, Genesove and Mullin (2001) which describes how the sugar cartel in the U.S. (1927-1936) colluded on business practices so as to facilitate tacit collusion on prices.

${ }^{4}$ Harrington (2006), for example, contains a detailed description of about twenty European cartel cases over 2000-2004. This study illustrates the remarkable variety in hard core cartels regarding both their content and their organization.

${ }^{5}$ OECD report (1998).
} 
of its sales. In this situation, there exists a hard core cartel that leads to an increase of allocative efficiency. Moreover, such a cartel allows for a substantial increase of firm profits as it reduces the amount of unprofitable sales and improves the pricecost margin on remaining sales. A welfare-enhancing strong cartel exists whenever there is a difference in unit costs at competitive production levels. In this case, individual and total profits can increase by shifting production from the inefficient firm to the efficient firm. It is shown that there always exists a cartel contract for which this profit increase dominates the loss in consumer surplus. Finally, we find that a welfare-enhancing weak cartel exists when the difference in unit costs is sufficiently large. Here, the price increase that results from the cartel is sufficient to compensate the inefficient firm for reducing its outputs. At the same time, this price effect should have a limited impact on consumer welfare in order for aggregate welfare to increase, which requires market demand to be sufficiently inelastic.

We are certainly not the first to point out the potentially welfare-enhancing effects of cartels. In the literature, one can find at least three main arguments indicating how horizontal collusion may promote social welfare. One strand of work argues that the per se prohibition should only apply to 'naked cartels', i.e., those contracts that are not ancillary to cooperative productive activity engaged in by the cartel members. This is essentially the view of the Chicago school of economics. The key argument is that when business practices such as price-fixing or market division form an essential part of a bigger arrangement between firms, then a cartel could potentially increase productive efficiency more than it reduces allocative efficiency. ${ }^{6}$ For instance, a cartel between sellers may increase social welfare when participating firms advertise jointly using media that they cannot afford individually, even though this requires an agreement upon prices that will be advertised. ${ }^{7}$ In fact, deterring or prosecuting efficient cartels could result in higher market prices as unit production costs will be higher in absence of the cartel. ${ }^{8}$

A second strand of literature highlights the possibility that unrestricted competition may not necessarily lead to a competitive equilibrium. Most notably, a competitive equilibrium may be absent in industries with large fixed costs and decreasing long-run average costs. That is, with increasing returns markets may have

\footnotetext{
${ }^{6}$ This is also the prime rationale for exempting export cartels from antitrust laws. First, the cartel allows for higher selling prices and, second, members can save costs, e.g., because they can use one and the same sales organization. Within a country, therefore, a cartel is likely to increase productive efficiency more than it reduces allocative efficiency, because costs due to a misallocation of resources are expected to be borne mainly by foreign customers. See Dick (1996) for a detailed discussion and analysis of the Webb-Pomerene Export Trade Act of 1918, which made cartel arrangements between U.S. exporters legal. However, it is doubtful if export cartels are beneficial for social welfare of trading nations together.

${ }^{7}$ See Bork (1993, p. 278).

${ }^{8}$ Sproul (1993), for example, finds that prices charged by firms indicted for price fixing gradually rose over the years following the indictment. As the author suggests, one potential explanation for this rather surprising result is that firms had established an economically efficient cartel.
} 
an empty core. ${ }^{9}$ This basically means that, even when firms are willing to compete, competition is not viable in certain markets. As a result, some sort of strategy coordination between firms is required to maintain an industry, thereby contributing to social welfare. One particular solution for these type of markets is to allow sellers to establish sales quotas. ${ }^{10}$ Such a hard core cartel would be welfare-enhancing as it saves a surplus generating business that would not exists with unrestricted competition. It is noteworthy that the cost conditions under which the core may be empty sometimes seem to describe quite closely the cost structure in manufacturing industries such as cement and steel; industries that have witnessed repeatedly hard core cartel behavior. ${ }^{11}$

A third strand of work shows that naked cartels may result in higher welfare standards even in markets with constant or decreasing returns. Taking a dynamic approach, it can be argued that cartels may (temporarily) lead to an increase (or stabilization) instead of a decrease in industry output. ${ }^{12}$ For example, under the assumption that firms are risk-averse, Dewey (1979) argues that a cartel will attract additional production given that barriers to entry are limited. ${ }^{13}$ In a related vein, Rotemberg (1998) shows that with imperfect financial markets and demand uncertainty cartels may lead to higher output levels than under (perfect) competition. The reason is that the additional profits that result from the cartel either encourages entry or provides cartel members with the incentive to invest in production capacity. This is confirmed by Fershtman and Pakes (2000), which studies collusion in a structural dynamic setting. They find that collusion may yield more and higher quality products, which more than compensates consumers for collusive prices. Finally, in the context of an infinitely repeated game with quantity competition and demand shocks, Montero and Guzmán (2005) shows that, under certain conditions, a profit-maximizing incomplete cartel may find it optimal to extend production beyond competitive levels. It should be noted, however, that cartels leading to an increase in industry output do not necessarily result in higher welfare standards compared to the competitive alternative. This is so because the increase in consumer surplus may be more than offset by a loss in producer surplus. ${ }^{14}$

\footnotetext{
${ }^{9}$ See Telser (1996).

${ }^{10}$ See, for instance, Sjostrom (1989) in which it is suggested that cartel behavior in ocean shipping is an attempt to solve the problem of an empty core.

${ }^{11}$ See, for example, Bittlingmayer (1982) which argues that the empty core theory is likely to have applied to the classic Addyston Pipe antitrust case. U.S. v. Addyston Pipe and Steel Co., 85 Fed. 271 (6th Cir. 1898).

${ }^{12}$ For example, Kinghorn (1996) and Troesken (1989) find empirical support for expansion of output by cartels. See also Bittlingmayer (1995) which shows that the National Industrial Recovery Act (NIRA), which was an essential part of Franklin Roosevelt's New Deal of 1933, had no significant effects on real output. This contrasts, however, with Taylor (2002) which shows that the NIRA led the U.S. manufacturing industry to reduce outputs.

${ }^{13} \mathrm{It}$ is noteworthy that this paper triggered quite a few comments, which perhaps also illustrates the controversy of this topic. See the American Economic Review, Vol. 72, No. 1, 1982.

${ }^{14}$ Röller and Steen (2006), for example, studies a hard core cartel arrangement in the Norwegian
} 
In contrast to the above references, we provide a complete characterization for the existence of welfare-enhancing hard core cartels. Our contribution differs from the existing literature in three additional respects. First, we solely focus on naked cartels, i.e., cartel agreements that are not accompanied by coordination of productive activities. Second, we only consider markets with a non-empty core. Third, we assume that hard core cartels cause a reduction in industry production. Thus, our paper is complementary in that we focus on naked hard core cartels that lead to a reduction in total industry supply in markets in which a competitive equilibrium exists. As we are primarily interested in the welfare effects, we will abstract from issues related to the formation and sustainability of cartels. That is to say, throughout the paper, we assume that profitable cartels are viable. ${ }^{15}$

This paper proceeds as follows. In the next section, the model is described and we establish necessary and sufficient conditions for the existence of an individually rational naked hard core cartel contract. In Section 3, these conditions are analyzed in more detail. In Section 4, we provide some applications and examine to what extent the conditions may hold in traditional price and quantity competition models. The robustness of our main results is discussed in Section 5. Among other things, we discuss how customers can benefit from a hard core cartel agreement. A simple illustration of this possibility is presented in Appendix A. In Section 6, we summarize our main findings and outline avenues for future research. All proofs are in Appendix B.

\section{Model and Conditions}

Consider an industry with two firms $i=1,2$ selling a homogeneous product. Total cost of producing a quantity $q_{i}$ is given by the cost function $C_{i}\left(q_{i}\right)$, which we assume to be increasing and convex, i.e., $C_{i}^{\prime}\left(q_{i}\right)>0$ and $C_{i}^{\prime \prime}\left(q_{i}\right) \geq 0$ for all $q_{i}>0$. Total industry production is denoted by $Q=q_{1}+q_{2}$ and the inverse market demand function is $p(Q)$, which is twice continuously differentiable with $p^{\prime}(Q)<0$ and $p^{\prime \prime}(Q) \leq 0$ at all $Q>0$. Thus, for some given price-quantity combination $(p(Q), Q)$, firm $i$ 's profit $\pi_{i}$ and the net consumer surplus $C S$ are respectively given by

$$
\pi_{i}=p(Q) q_{i}-C_{i}\left(q_{i}\right), \text { for } i=1,2,
$$

and

$$
C S=\int_{0}^{Q} p(x) d x-p(Q) Q .
$$

cement industry. They find that industry output increased during the cartel regime and that domestic customers actually benefited from the cartel. However, it is also shown that total surplus would have been higher in competition. See Matsui (1989) for a theoretical analysis of how a horizontal cartel may benefit consumers, while making firms worse off.

${ }^{15}$ We discuss the implications of this assumption in Section 5. 
Society's welfare $W$ is defined as the sum of firm profits and consumer surplus:

$$
W=\pi_{1}+\pi_{2}+C S=\int_{0}^{Q} p(x) d x-C_{1}\left(q_{1}\right)-C_{2}\left(q_{2}\right) .
$$

Hence, for any given $(p(Q), Q)$, total welfare equals gross consumer surplus minus the total costs of production. In what follows, competitive and collusive price-quantity combinations are respectively denoted by $\left(p^{*}, Q^{*}\right)$ and $\left(p^{c}, Q^{c}\right)$, where $p^{*} \equiv p\left(Q^{*}\right)$ and $p^{c} \equiv p\left(Q^{c}\right)$. As our focus is on hard core cartels that cause a reduction of industry output, we assume $Q^{c}<Q^{*}$ (and therefore $p^{c}>p^{*}$ ). Our analysis does not require any assumption on how $\left(p^{*}, Q^{*}\right)$ emerges. Yet, it is natural to think of $\left(p^{*}, Q^{*}\right)$ as a competitive equilibrium outcome of some oligopoly game. In Section 4 , we therefore explore to what extent our results apply in familiar duopoly models.

Finally, we make the following additional assumption

Axiom $1 C_{1}^{\prime}\left(q_{1}^{*}\right) \leq C_{2}^{\prime}\left(q_{2}^{*}\right)$ and $q_{1}^{*}, q_{2}^{*}>0$.

The first part of Axiom 1 states that, at competitive output levels, marginal production costs of firm 1 are weakly lower than the marginal production costs of firm 2, which is without loss of generality. The second part of Axiom 1 requires both firms to be active in competition.

Before discussing the welfare-enhancing potential of cartels, let us clarify what we mean by the adjective 'welfare-enhancing'. We consider a cartel contract to be welfare-enhancing whenever the agreement results in more aggregate welfare than the competitive alternative. Thus, a cartel agreement $\left(p^{c}, Q^{c}\right)$ is welfare-enhancing if $W^{c}>W^{*}$, which is equivalent to

$$
C_{1}\left(q_{1}^{*}\right)+C_{2}\left(q_{2}^{*}\right)-C_{1}\left(q_{1}^{c}\right)-C_{2}\left(q_{2}^{c}\right)>\int_{Q^{c}}^{Q^{*}} p(Q) d Q .
$$

A hard core cartel arrangement will therefore result in an increase of aggregate welfare only when the decrease in total production costs is strictly larger than the loss in gross consumer surplus. Condition (4) captures the welfare trade-off that is often present when firms cooperate. For example, in a classic discussion of mergers, Williamson (1968) emphasizes the issue of whether the increase in productive efficiency more than makes up for the loss in allocative efficiency, which typically results from higher market concentration. Similarly, by achieving a sufficiently large cost reduction, naked hard core cartels might have a positive effect on welfare, although in our model this will not result from economic integration.

Additionally, we require both firms to benefit from the cartel. Therefore, we only consider cartel agreements for which profits of both firms are strictly higher than in competition. We distinguish two types of cartel arrangements; one that includes the possibility of making side payments (strong cartel) and another in which such 
monetary transfers are absent (weak cartel). ${ }^{16}$ The following definition formalizes this participation constraint.

Definition $2 A$ hard core cartel agreement $\left(p^{c}, Q^{c}\right)$ is individually rational if

(i) $\pi_{i}^{c}>\pi_{i}^{*}, \forall i=1,2$ (weak cartel), or

(ii) $\sum_{i=1,2} \pi_{i}^{c}>\sum_{i=1,2} \pi_{i}^{*}$ (strong cartel).

Notice that the first part of this definition is stronger than the second as Definition 2(i) implies Definition 2(ii), but not vice versa. However, to ensure individual rationality, we implicitly assume that total cartel profit of a strong cartel will be distributed such that $\pi_{i}^{c}>\pi_{i}^{*}, \forall i=1,2$.

The main issue is now to establish conditions under which hard core cartels are both welfare-enhancing and individually rational. To that end, consider some competitive situation $\left(p^{*}, Q^{*}\right)$. The impact of a change in output on total welfare, as defined in (3) above, from the point $\left(p^{*}, Q^{*}\right)$ in the direction $\mathbf{u}=\left(u_{1}, u_{2}\right)$, is given by the directional derivative

$$
u_{1}\left(p^{*}-C_{1}^{\prime}\left(q_{1}^{*}\right)\right)+u_{2}\left(p^{*}-C_{2}^{\prime}\left(q_{2}^{*}\right)\right),
$$

where $\mathbf{u}$ is a unit length vector.

The impact of a change in production on firm profits and total profit from the competitive point in the direction $\mathbf{u}=\left(u_{1}, u_{2}\right)$ is respectively given by

$$
u_{i}\left(p^{*}+p^{* \prime} q_{i}^{*}-C_{i}^{\prime}\left(q_{i}^{*}\right)\right)+u_{j}\left(p^{* \prime} q_{i}^{*}\right), \text { for } i=1,2 \text {. }
$$

and

$$
u_{1}\left(p^{*}-C_{1}^{\prime}\left(q_{1}^{*}\right)\right)+u_{2}\left(p^{*}-C_{2}^{\prime}\left(q_{2}^{*}\right)\right)+\left(u_{1}+u_{2}\right) p^{* \prime} Q^{*} .
$$

As our focus is on cartel contracts that lead to a reduction of industry output, we assume in the following that $u_{1}+u_{2}<0$.

For a decrease in industry production to have a positive effect on total welfare, we must have that (5) is positive. Thus, a welfare-enhancing cartel exists if there is a direction $\mathbf{u}$ for which the following condition is satisfied.

Condition $3 u_{1}\left(p^{*}-C_{1}^{\prime}\left(q_{1}^{*}\right)\right)+u_{2}\left(p^{*}-C_{2}^{\prime}\left(q_{2}^{*}\right)\right)>0$ with $u_{1}+u_{2}<0$.

Likewise, a decrease in output in the direction $\mathbf{u}$ will have a positive effect on individual and total profits when (6) and (7) are positive. Condition $4(i)$, in case of a weak cartel, and Condition 4(ii), in case of a strong cartel, must hold for some direction $\mathbf{u}$ to prove that there exists a cartel agreement that is individually rational.

\footnotetext{
${ }^{16}$ This is a common distinction in the literature on collusion. See, for example, Pesendorfer (2000).
} 
Condition $4(i) u_{i}\left(p^{*}+p^{* \prime} q_{i}^{*}-C_{i}^{\prime}\left(q_{i}^{*}\right)\right)+u_{j}\left(p^{* \prime} q_{i}^{*}\right)>0$, for $i=1,2$ with $u_{1}+u_{2}<0$ (weak cartel). (strong cartel).

(ii) $u_{1}\left(p^{*}-C_{1}^{\prime}\left(q_{1}^{*}\right)\right)+u_{2}\left(p^{*}-C_{2}^{\prime}\left(q_{2}^{*}\right)\right)+\left(u_{1}+u_{2}\right) p^{* \prime} Q^{*}>0$ with $u_{1}+u_{2}<0$

In sum, if Condition 3 holds, then there exists a cartel agreement for which $W^{c}>$ $W^{*}$ and if Condition 4 holds, then there exists a cartel agreement for which $\pi_{i}^{c}>\pi_{i}^{*}$, for $i=1,2$. Thus, Condition 3 in conjunction with Condition 4 marks situations in which there exists an individual rational welfare-enhancing cartel arrangement. Notice that, due to the concavity of both (1) and (3), Conditions 3 and 4 are both necessary and sufficient. ${ }^{17}$ In the next section, we analyze these conditions in more detail.

\section{Analysis and Results}

In the previous section, we have listed necessary and sufficient conditions that must hold for a hard core cartel to be individually rational and welfare-enhancing. Starting from some competitive situation $\left(p^{*}, Q^{*}\right)$, the key question is whether there exists a direction $\mathbf{u}=\left(u_{1}, u_{2}\right)$ such that Condition 3 and 4 hold simultaneously. If so, then there exists another higher point on the market demand curve $\left(p^{c}, Q^{c}\right)$ for which both profits and aggregate welfare are higher. In this section, we analyze these conditions and discuss their implications.

\subsection{Weak Cartels}

In focusing on hard core cartel contracts without side payments, the question is if and when Condition 3 and Condition $4(i)$ hold simultaneously. The following result provides a necessary condition for the existence of an individually rational welfareenhancing weak cartel.

Lemma 5 If there exists an individually rational welfare-enhancing weak cartel, then $\pi_{i}^{\prime}\left(q_{i}^{*}\right)<0$ for at least one firm $i$.

Hence, if an individually rational welfare-enhancing weak cartel exists, then at least one firm would be willing to cut back production. Yet, the competitive situation may be such that an uncoordinated reduction of output is not in a firm's best interest. In other words, restricting one's own output may not be an optimal strategy given the strategy adopted by competitors.

Using this result, we can specify necessary and sufficient conditions for the existence of an individually rational welfare-enhancing weak cartel.

${ }^{17}$ That is, $\frac{\partial^{2} \pi_{i}}{\partial q_{i}^{2}}<0$ and $\frac{\partial^{2} W}{\partial Q^{2}}<0$ so that both have a unique maximum. 
Theorem 6 There exists an individually rational welfare-enhancing weak cartel if and only if:

$$
p^{*}-C_{2}^{\prime}\left(q_{2}^{*}\right)<\max \left\{0, \frac{p^{* \prime} q_{2}^{*}\left(p^{*}-C_{1}^{\prime}\left(q_{1}^{*}\right)\right)}{p^{* \prime} q_{2}^{*}-\left(p^{*}-C_{1}^{\prime}\left(q_{1}^{*}\right)\right)}\right\} .
$$

This result shows that there are two situations in which an individually rational welfare-enhancing weak cartel exists. First, such a cartel exists when at least one firm makes a loss on (part of) its sales in competition, i.e., $p^{*}-C_{2}^{\prime}\left(q_{2}^{*}\right)<0$. To provide some intuition, suppose that both firms engage in the following cartel contract. Firm 1 keeps its output constant, while Firm 2 is reducing its production slightly. This agreement is individually rational as Firm 1 sells the same amount of products at a higher price, while Firm 2 avoids selling a loss-making item and enjoys a higher margin on its remaining sales. The cartel contract has a positive impact on total surplus as it prevents (part of) the losses from trade in competition and does not create a deadweight loss. In fact, in this case there exists a cartel that would lead to an increase of allocative efficiency.

Second, an individually rational welfare-enhancing weak cartel may exist when the price-cost margin is (weakly) positive for both firms at competitive production levels, i.e., $p^{*}-C_{2}^{\prime}\left(q_{2}^{*}\right) \geq 0$. Following Theorem 6 , such a cartel does exist whenever

$$
p\left(Q^{*}\right)-C_{2}^{\prime}\left(q_{2}^{*}\right)<\alpha\left(p\left(Q^{*}\right)-C_{1}^{\prime}\left(q_{1}^{*}\right)\right), \text { with } \alpha \equiv \frac{p^{* \prime} q_{2}^{*}}{p^{* \prime} q_{2}^{*}-\left(p^{*}-C_{1}^{\prime}\left(q_{1}^{*}\right)\right)} .
$$

Observe that (8) in combination with Axiom 1 implies that $p^{*}-C_{1}^{\prime}\left(q_{1}^{*}\right)>0$ and therefore $\alpha \in(0,1)$. For $(8)$ to apply, we then must have that $p^{*}-C_{1}^{\prime}\left(q_{1}^{*}\right)>p^{*}-C_{2}^{\prime}\left(q_{2}^{*}\right)$ or $C_{2}^{\prime}\left(q_{2}^{*}\right)>C_{1}^{\prime}\left(q_{1}^{*}\right)$, because $\alpha<1$.

Thus, given that the price-cost margin is positive for both firms, the existence of a welfare-enhancing weak cartel requires a difference in unit costs at competitive production levels. The following result shows that this difference must be sufficiently large, which depends on the price elasticity of demand $\varepsilon \equiv-\frac{\partial Q}{\partial p} \frac{p^{*}}{Q^{*}}$ and the market share of the less efficient firm $s_{2}=\frac{q_{2}^{*}}{Q^{*}}$.

Corollary 7 If $p^{*}-C_{2}^{\prime}\left(q_{2}^{*}\right) \geq 0$, then there exists an individually rational welfareenhancing weak cartel if and only if:

$$
p^{*}-C_{2}^{\prime}\left(q_{2}^{*}\right)<\frac{s_{2}}{\varepsilon\left(\frac{p^{*}-C_{1}^{\prime}\left(q_{1}^{*}\right)}{p^{*}}\right)}\left(C_{2}^{\prime}\left(q_{2}^{*}\right)-C_{1}^{\prime}\left(q_{1}^{*}\right)\right) .
$$

The intuition behind this result is as follows. Recall that, for an increase of aggregate welfare, profits must be sufficiently higher under a cartel regime. Given that total industry production is lower with a cartel, this implies that the less efficient firm has to reduce its output, while the more efficient firm has to increase its production 
(by a smaller amount). This has two effects. First, there is a total cost reduction resulting from a shift in production from the inefficient to the efficient firm. This positively affects both profits and welfare. Second, the output reduction (and price increase) caused by the cartel has a positive impact on profits, but a negative impact on welfare. For the cartel to be welfare-enhancing, we must have that the first effect dominates the second, which is the case when the difference in unit costs is sufficiently large. Notice that whether the difference in unit costs is sufficient in part depends on the price elasticity of demand. In particular, the required difference in productive efficiency is smaller the more inelastic is demand, all else equal. The reason is that the deadweight loss created by the cartel is positively related to the price elasticity of demand.

As to the individual rationality requirement, observe that the efficient firm always finds it in its interest to take part in this cartel, because it will sell more products at a higher price. However, the less efficient firm wants to participate only if it is sufficiently compensated for its losses due to lower output. This is the case when it experiences a sufficient increase in the price-cost margin of its remaining production. If the less efficient firm has a large market share, then the higher price-cost margin caused by the cartel has a significant impact as remaining production is still substantial. Thus, the above situation is more likely to apply, the larger the market share of the less efficient firm, all else equal. Also, the increase in the price-cost margin depends negatively on the elasticity of demand. Therefore, it is ceteris paribus easier to sufficiently compensate the less efficient firm when demand is relatively inelastic. Finally, the increase in price-cost margin is more likely to be sufficient when unit costs of the less efficient firm are relatively large in competition. The reason being that under a cartel regime it gives up part of its production for which profits are limited. As before, this makes it more likely that the higher mark-up on remaining production is sufficient to compensate for the loss in sales.

\subsection{Strong Cartels}

We now turn our attention to strong cartels. Thus, the issue is under what circumstances Condition 3 and Condition 4(ii) hold simultaneously. As the following Lemma indicates, it suffices to focus exclusively on Condition 3.

Lemma 8 If Condition 3 is satisfied, then Condition $4(i i)$ is satisfied.

Using the above result, the next theorem shows necessary and sufficient conditions for the existence of an individually rational welfare-enhancing strong cartel.

Theorem 9 There exists an individually rational welfare-enhancing strong cartel if and only if: 
(i) $C_{1}^{\prime}\left(q_{1}^{*}\right)<C_{2}^{\prime}\left(q_{2}^{*}\right)$, or

(ii) $C_{1}^{\prime}\left(q_{1}^{*}\right)=C_{2}^{\prime}\left(q_{2}^{*}\right)>p^{*}$.

The first part of Theorem 9 reveals that an individually rational welfare-enhancing strong cartel exists whenever there is a difference in unit costs at competitive production levels. To see that this is sufficient, note that in light of Axiom 1 it is possible to shift some production from the less efficient firm to the more efficient firm. If firms would keep total output constant (a one-to-one shift), then total profits would increase. In this case, consumer welfare remains unaffected so that total surplus would increase as well. As production is a continuous variable, there exists an output level that is smaller than but sufficiently close to $Q^{*}$ such that both profits and welfare are higher compared to the competitive alternative.

The second part of Theorem 9 shows that an individually rational welfare-enhancing strong cartel also exists when marginal production costs are equal and higher than the selling price at competitive production levels. This situation satisfies the condition of Theorem 6 above. Like with weak cartels, when the unit costs of the last item(s) sold exceed price, then it is profitable to cut back production. Lowering production avoids (part of) the unprofitable sales and yields an increase of the price-cost margin on the remaining sales. If the reduction in outputs is limited, then a hard core cartel increases instead of decreases allocative efficiency and is thereby contributing to social welfare.

\section{Applications}

So far, the starting point of our analysis has been some competitive point on the market demand curve $\left(p^{*}, Q^{*}\right)$. Clearly, whether or not Conditions 3 and 4 can be satisfied simultaneously directly depends on this competitive situation. Although it is not required for the derivation of our results, it is natural to think of $\left(p^{*}, Q^{*}\right)$ as a competitive equilibrium outcome of some oligopoly game. It is therefore instructive to explore the extent to which our results apply in familiar duopoly models. In this section, we analyze if and when welfare-enhancing hard core cartels exist in basic "textbook" models of price and quantity competition. In summarizing our results, both welfare-enhancing weak and strong cartels might exist when marginal costs are increasing and firms compete in price. If firms compete in quantity, then a welfareenhancing cartel exists when firms use side payments and have different unit costs at competitive production levels.

\subsection{Price Competition}

Consider an industry with two profit-maximizing firms producing a homogeneous product. To ensure that best responses are well-defined, we assume a discrete set of 
feasible prices. Firms choose their prices simultaneously from the set $\{0, \varepsilon, 2 \varepsilon, \ldots\}$, with $\varepsilon$ being positive and small. Consumers buy from the firm with the lowest price. If both charge the same price, then they share the market equally. The market demand function is given by $Q(p)$. We further assume that firms always meet demand (the market is clearing). Profits of both firms are then of the following structure

$$
\pi_{i}= \begin{cases}p_{i} \cdot Q\left(p_{i}\right)-C_{i}(Q) & \text { if } p_{i}<p_{j} \\ p_{i} \cdot \frac{1}{2} Q\left(p_{i}\right)-C_{i}\left(\frac{1}{2} Q\right) & \text { if } p_{i}=p_{j} \\ 0 & \text { if } p_{i}>p_{j}\end{cases}
$$

The outcome of this game is a Bertrand Nash equilibrium when none of the firms finds it in its interest to change its price given the price set by its rival.

Using this basic price competition model, we get the following results.

Proposition 10 (i) If $C_{i}^{\prime}(\cdot)>0$ and $C_{i}^{\prime \prime}(\cdot)=0$, for $i=1,2$, then there exists no Bertrand Nash equilibrium for which Conditions 3 and $4(i)$ can be satisfied simultaneously, and (ii) If $C_{i}^{\prime}(\cdot)>0$ and $C_{i}^{\prime \prime}(\cdot)>0$, for $i=1,2$, then there exists a Bertrand Nash equilibrium for which Conditions 3 and 4 (i) can be satisfied simultaneously.

Hence, given the above model specifications, firms cannot form a welfare-enhancing weak cartel when unit costs are constant. By contrast, a welfare-enhancing weak cartel may exist when unit costs are increasing. In the latter case, there always exists a Bertrand Nash equilibrium for which at least one of the firms has marginal costs that exceed price at competitive production levels. By Theorem 6, we know that this is sufficient for the existence of an individually rational welfare-enhancing weak cartel.

As to welfare-enhancing strong cartels, we get a similar result. The main difference is that the set of competitive equilibria for which a welfare-enhancing strong cartel exists is typically larger.

Proposition $11(i)$ If $C_{i}^{\prime}(\cdot)>0$ and $C_{i}^{\prime \prime}(\cdot)=0$, for $i=1,2$, then there exists no Bertrand Nash equilibrium for which Conditions 3 and 4 (ii) can be satisfied simultaneously, and (ii) If $C_{i}^{\prime}(\cdot)>0$ and $C_{i}^{\prime \prime}(\cdot)>0$, for $i=1,2$, then there exists a Bertrand Nash equilibrium for which Conditions 3 and 4 (ii) can be satisfied simultaneously.

The following example illustrates the possibility for a welfare-enhancing cartel when firms compete in price.

Example 12 Suppose market demand is $Q=1-p$. Assume further that both firms have identical cost functions of the form $C_{i}\left(q_{i}\right)=\frac{1}{4} q_{i}^{2}$. Thus, individual profits are given by

$$
\pi_{i}=p_{i} q_{i}-\frac{1}{4} q_{i}^{2}, \text { for } i=1,2 \text {. }
$$


As the situation is symmetric, both firms will charge the same price in equilibrium. Let $p^{\circ}=p_{1}^{*}=p_{2}^{*}$ and $\pi=\pi_{1}+\pi_{2}$. In competition, total profits and social welfare are then respectively

$$
\pi=\left(p^{\circ}-\frac{1}{8}\left(1-p^{\circ}\right)\right)\left(1-p^{\circ}\right)
$$

and

$$
W=\left(p^{\circ}-\frac{1}{8}\left(1-p^{\circ}\right)\right)\left(1-p^{\circ}\right)+\frac{1}{2}\left(1-p^{\circ}\right)^{2}
$$

Now suppose both firms set $p^{\circ}=\frac{1}{8}$, which yields profits $\pi_{i}=\frac{7}{1024}$, for $i=1,2$. Since $\pi_{i}>0$, none of the firms finds it profitable to raise its own price. Moreover, none of the firms finds it profitable to undercut the price of its rival as this would yield a profit of $\pi_{i}=\left(\frac{1}{8}-\frac{1}{4} \frac{7}{8}\right) \frac{1}{2} \frac{7}{8}=-\frac{21}{512}$, for $i=1,2$. Thus, $p^{\circ}=\frac{1}{8}$ is a Bertrand Nash equilibrium and the corresponding total surplus is $W^{*}=\frac{203}{512}$.

In this situation, both firms could form a welfare-enhancing weak cartel by, for example, fixing the price at $p^{c}=\frac{1}{5}$. With $p^{c}=\frac{1}{5}$, profits are equal to $\pi_{i}=\frac{1}{25}>\frac{7}{1024}$, for $i=1,2$, and total welfare is equal to $W^{c}=\frac{2}{5}>\frac{203}{512}$. Hence, this cartel would lead to an increase of individual profits and aggregate welfare.

\subsection{Quantity Competition}

We now turn to the question whether a welfare-enhancing hard core cartel is a possibility in a basic Cournot model with homogeneous goods. In this case, both firms choose their outputs simultaneously. In competition, firms independently choose production levels to maximize profits, which implies that

$$
p^{\prime}(Q) q_{i}+p(Q)-C_{i}^{\prime}\left(q_{i}\right)=0, \text { for } i=1,2 .
$$

A solution $\left(p^{*}, Q^{*}\right)$ to $(9)$ is here referred to as a Cournot Nash equilibrium.

The following result shows that there exists no individually rational welfareenhancing weak cartel when quantity is the strategic variable.

Proposition 13 There exists no Cournot Nash equilibrium for which Conditions 3 and 4 (i) can be satisfied simultaneously.

By Lemma 5 above, we know that a necessary condition for the existence of a welfare-enhancing weak cartel is that at least one firm would prefer to cut back production. Clearly, as firms will choose their outputs optimally none of them will produce 'too much' in competition.

In contrast, an individually rational welfare-enhancing strong cartel always exists as long as there is a difference in unit costs at competitive production levels.

Proposition 14 In Cournot competition, Conditions 3 and 4 (ii) can be satisfied simultaneously if and only if $C_{1}^{\prime}\left(q_{1}^{*}\right)<C_{2}^{\prime}\left(q_{2}^{*}\right)$. 
In light of Theorem 9, a difference in unit costs is sufficient for the existence of a welfare-enhancing strong cartel. The only other situation in which such a cartel exists is when unit costs are equal and exceed price. However, this cannot occur in Cournot competition. That is, (9) reveals that in a Cournot Nash equilibrium both firms have a positive price-cost margin.

The following example illustrates the possibility for a welfare-enhancing strong cartel in a standard Cournot model.

Example 15 Suppose the (inverse) market demand is $p(Q)=1-Q$. Unit costs of both firms are constant. Let $C_{1}^{\prime}(\cdot)=0$ and $C_{2}^{\prime}(\cdot)=c$ with $c \in\left(0, \frac{1}{2}\right)$. Profits of firm 1 and firm 2 are then given by

$$
\pi_{1}=\left(1-\left(q_{1}+q_{2}\right)\right) q_{1}
$$

and

$$
\pi_{2}=\left(1-\left(q_{1}+q_{2}\right)-c\right) q_{2}
$$

Total welfare is equal to

$$
W=\left(1-\left(q_{1}+q_{2}\right)\right)\left(q_{1}+q_{2}\right)-c q_{2}+\frac{1}{2}\left(q_{1}+q_{2}\right)^{2} .
$$

In this case, the Cournot Nash equilibrium pair of quantities is $\left(q_{1}^{*}, q_{2}^{*}\right)=\left(\frac{1+c}{3}, \frac{1-2 c}{3}\right)$. Total competitive profits are $\pi^{*}=\pi_{1}^{*}+\pi_{2}^{*}=\frac{2-2 c+5 c^{2}}{9}$ and social welfare in competition is $W^{*}=\frac{8(1-c)+11 c^{2}}{18}$.

Now suppose both firms form a strong cartel by agreeing that the entire competitive output will be produced by the efficient firm (firm 1). Such an agreement would lead to an increase in total profits and aggregate welfare of $\frac{c-2 c^{2}}{3}$. As both the profit and welfare functions are continuous, there exists a nondegenerate interval of values for $q_{1}^{c}\left(<Q^{*}\right)$ such that total industry production is lower, but total profits and welfare are higher.

\section{Discussion}

In a simple but fairly general setting, we have established necessary and sufficient conditions for the existence of an individually rational and welfare-enhancing naked hard core cartel. In thinking about these results, there are at least three questions that come to mind. First, if and to what extent do these conditions apply in practice? Second, to what extent are our results model specific? Most notably, can we expect to find similar results in more sophisticated settings? Third, how are the results affected if we eliminate profits from the welfare function, i.e., if we identify aggregate welfare with consumer surplus? We briefly discuss each of these issues below.

The first question concerns the degree of realism of the results derived above. We have used a framework that is quite similar to the static "textbook" model of collusion 
that is frequently applied to illustrate the harmful effects of hard core cartels. In this setting, we have demonstrated that one can identify situations in which hard core cartels may lead to an increase of total surplus. Clearly, whether and how often such situations occur in practice is ultimately an empirical question and is likely to depend on the industry under consideration. However, the conditions under which a welfare-enhancing hard core cartel exists certainly do not seem to hold in rare cases only. For instance, firms having different unit costs at competitive production levels is likely to be the rule rather than the exception.

Additionally, it should be emphasized that the mere fact that a welfare-enhancing hard core cartel exists does not imply that firms will actually form such an agreement. Even though Condition 4 guarantees that it might be individually rational to establish a welfare-enhancing cartel agreement, firms often have a whole set of sustainable collusive strategies available and it seems unlikely that every viable cartel contract will yield an increase of aggregate welfare. In the theory of collusion, it is common to assume that firms will choose the cartel contract(s) that maximize firms' profits. In the above framework, it appears difficult to draw general conclusions about whether and when the set of welfare-enhancing cartels contains the profit-maximizing cartel. However, to illustrate that this possibility is real, consider the following example.

Example 16 Suppose the inverse market demand function is given by $Q=1-10 p$ and that firms have identical cost functions $C\left(q_{i}\right)=\frac{1}{4} q_{i}^{2}$. Thus, unit costs are $\frac{1}{2} q_{i}$, for $i=1,2$. Total profits and consumer surplus are then respectively given by

$$
\pi=\pi_{1}+\pi_{2}=(1-10 p)\left(p-\frac{1}{8}(1-10 p)\right)
$$

and

$$
C S=\frac{1}{2}(1-10 p)\left(\frac{1}{10}-p\right) .
$$

Hence, total welfare equals,

$$
W=(1-10 p)\left(p-\frac{1}{8}(1-10 p)\right)+\frac{1}{2}(1-10 p)\left(\frac{1}{10}-p\right) .
$$

Now suppose that $p=\frac{1}{18}$ (so that both firms make zero profits in competition). In this case, aggregate welfare is equal to $W=\frac{8}{810}$. A profit-maximizing cartel would charge a cartel price of $p^{c}=\frac{7}{90}$, which yields total cartel profits equal to $\pi^{c}=\frac{1}{90}$ and total welfare $W^{c}=\frac{11}{810}$. Consequently, a profit-maximizing cartel may lead to an increase of aggregate welfare.

A second issue is to what extent our results are model specific. For example, one may wonder to what extent our results will hold in a dynamic setting. In our analysis, we abstracted from issues related to cartel formation and cartel sustainability. Note, however, that the requirement that both firms benefit from the cartel implies that 
forming the cartel is individually rational. Moreover, in the context of an infinitely repeated game, such an agreement can be enforced by standard means (e.g., trigger strategies) provided that both firms are sufficiently patient. Therefore, our analysis marks a lower bound on the size of the set of welfare-enhancing cartel contracts. A dynamic model would, for instance, allow for an analysis of the welfare impact of socalled structural crisis cartels. During an economic crisis such cartel agreements may allow for a smooth reconstruction of the industry and an orderly withdrawal of firms from the market. In the long run, crisis cartels may be superior in terms of social welfare as excess capacity during recessions may lead to destructive competition. ${ }^{18}$ More generally, taking a dynamic approach will, in all likelihood, enlarge the set of welfare-enhancing hard core cartel contracts, because there typically are more possibilities to save on total costs of production.

Moreover, our focus has been on what is arguably the "most evil" of all cartel contracts; those that exclusively lead to lower output and higher prices. In the above setting, whether or not such agreements yield an increase in total surplus solely depends on the condition as given in (4). This condition reveals that what is needed for a hard core cartel to be welfare-enhancing is a sufficient decrease in total production costs. We have derived results for given cost functions. Clearly, one could extent our setting by taking account of potential synergies or additional costs of production. For example, Doyle and Han (2009) analyze a model in which colluding firms form so-called buyer groups. This buyer group may effectively lower marginal production costs which, depending on the magnitude, may benefit both customers and society at large. Deltas, Salvo and Vasconcelos (2009) use a spatial setting to show that collusion may promote the welfare of both customers and society when savings on transportation costs under the cartel regime are substantial. These contributions suggest that allowing for "a shift of the cost functions" is likely to enlarge the set of welfare-enhancing hard core cartels. In a similar vein, welfare-enhancing hard core cartels may exist when there are additional costs of production that are not incurred by firms. This possibility is illustrated graphically in Appendix A.

A final issue that warrants discussion is our notion of social welfare. Although it is common in the literature to define social welfare to be the sum of consumer and producer surplus, one could make the case that firm profits should not be part of the welfare function. Posner (1975), for example, argues in case of monopoly that supra-normal profits will evaporate due to rent-seeking efforts to obtain the beneficial position. In case of horizontal collusion one could similarly conjecture that at least part of firm profits will be wasted to form and maintain the cartel. The importance of consumer welfare is also emphasized in antitrust practice. For instance, to qualify for an exemption on the basis of Article 81(3) of the EC Treaty it is required that customers receive a "fair share" of the benefits of the agreement. Therefore, it is of

\footnotetext{
${ }^{18}$ In the U.S., structural crisis cartels, like other hard core cartels, are subject to the per se rule under the Sherman Act. By contrast, in Europe these type of cartels are sometimes permitted. See, for instance, Commission Decision 4 July 1984 OJ L 207/17 (EC synthetic fibres industry).
} 
interest to see how our results would be affected when firm profits are excluded from the welfare function.

As we have only considered cartel agreements that led to a reduction of industry output and higher prices, it is clear that consumers are worse off. That is, in our setting, a hard core cartel makes customers pay more for less. Note, however, that this is partly due to the rather narrow way in which we defined a hard core cartel. For example, customers would be unaffected if we would also consider horizontal agreements in which the efficient firm raises production and the inefficient firm lowers production in such a way that total production remains unaltered. A strong cartel that does not affect the competitive price-quantity combination would yield a Pareto improvement. Moreover, not every output reduction and price increase makes consumers worse off per se. Suppose, for instance, that trade yields severe negative externalities. It is well-known that in the presence of negative externalities competitive markets will produce too much from a social welfare perspective. In this case, a reduction of industry output might not only benefit producers, but also consumers on other markets (see Appendix A).

Furthermore, given that the conditions of an individually rational welfare-enhancing cartel hold, a hard core cartel could potentially compensate customers. As in this case total surplus is higher under the cartel regime, both firms and consumers could benefit from the arrangement. In other words, the fact that a hard core cartel may generate a "larger pie" implies that a true Pareto improvement is within reach. Following the Kaldor-Hicks principle, the winners could compensate the losers to obtain such a Pareto improvement. Although there might be some practical complications, in principle it would be feasible to implement such a system. More generally, the mere fact that even naked hard core cartels may lead to an increase of the gains from trade provides opportunities for both customers and society as a whole. At a minimum, it raises doubts about the per se standard of antitrust analysis and we believe that the possibility of occasionally allowing these forms of cooperation deserves to be reconsidered.

\section{Concluding Remarks}

Cartels come in many different forms and the merits and demerits of these type of organizations have been heavily debated at least since the enactment of the Sherman Act in 1890. There is, however, wide consensus nowadays that cartels which exclusively limit production and raise prices are detrimental to social welfare. In most capitalist societies, such so-called naked hard core cartel arrangements are therefore illegal per se. In this paper, we have questioned this conventional wisdom. In a simple but fairly general setting, we have derived necessary and sufficient conditions for a hard core cartel to lead to an increase of both profits and aggregate welfare. We considered both strong and weak hard core cartel contracts and found that $(i)$ a welfare-enhancing strong cartel exists when firms have different unit production 
costs at competitive output levels, $(i i)$ a welfare-enhancing weak cartel exists if this difference is sufficiently large, and (iii) both types can be welfare-enhancing when at least one firm makes a loss on part of its sales in competition.

If and how often these conditions hold in the real world is ultimately an empirical question and is likely to depend on the (type of) industry under consideration. Yet, the possibility seems real. Our analysis, in addition to the references cited in the introduction above, therefore begs the question of how cartels should be dealt with in antitrust practice. At a minimum, it is questionable whether the per se rule standard of antitrust analysis is optimal in terms of social welfare. An interesting and important research question is to explore what optimal antitrust enforcement looks like in a setting where the (unknown) pool of potential cartels contains both "good cartels" and "bad cartels". An improvement of the antitrust system might be within reach if one would have a means to discriminate between efficient and inefficient cartel arrangements. Clearly, determining whether or not a potential cartel harms or contributes to social welfare is not an easy task. We believe the answer lies in modifying the current system in such a way that potential "good cartels" have an incentive to reveal their type. When feasible, such a system would allow for the possibility to grant an exemption on the basis of the welfare effects of the potential cartel agreement. It is, however, a priori unclear whether and in what way relaxing the per se rule would indeed lead to higher welfare standards. We leave this issue for future research. 


\section{Appendix A: Negative Externalities}

Although it may not be their intention, firms that engage in a cartel can (partly) offset losses due to market failure. This is particularly true in industries that exhibit severe negative externalities in production. It has long been recognized that competitive markets may yield too much output from a social welfare perspective when firms do not take account of all costs associated with the production of the good or service. Thus, in the presence of negative externalities, a naked hard core cartel arrangement is beneficial in terms of social welfare when the agreed upon cartel production is closer to the social optimum. In this section, we present a simple graphical analysis to illustrate this point.

The potential impact of a naked hard core cartel in an industry with negative externalities in production is shown graphically in Figure 1, which depicts a single market with linear downward-sloping demand $D$. The corresponding marginal revenue curve is twice as steep and labelled $M R$. The supply curve is based on the marginal private costs of production incurred by firms and denoted $S^{p}$. Therefore, the competitive equilibrium price-output combination $\left(p^{*}, Q^{*}\right)$ is such that $D$ equals $S^{p}$. When there are negative externalities in production, however, there are additional costs not incurred by firms, but by third parties (or society as a whole). For simplicity, it is assumed that these 'marginal damages of production' $(M D)$ are linear in production (line not drawn). Marginal social cost of production then equals $S^{p}$ plus $M D$ and is denoted $S^{s}$ in Figure 1. Welfare maximization therefore requires a price-quantity combination $\left(p^{s}, Q^{s}\right)$, which is the point where $D$ intersects with $S^{s}$.

In competition, total welfare (consumer plus producer surplus) is given by the area $a d p^{*}+p^{*} d c-c d e=a d c-c d e=a b c-b d e .{ }^{19}$ With the optimal price-quantity combination $\left(p^{s}, Q^{s}\right)$, total welfare is given by de area $a b p^{s}+p^{s} b f c-b c f=a b f c-b c f=$ $a b c$. As $a b c>a b c-b d e$, total welfare is higher for $\left(p^{s}, Q^{s}\right)$ than for $\left(p^{*}, Q^{*}\right)$. Hence, in competition too much is produced from a social welfare point of view and a reduction of industry output (and an increase in prices) will potentially lead to higher welfare standards.

Now suppose that firms establish a hard core cartel contract. In Figure 1, a profitmaximizing cartel would reduce total market output to $Q^{c}$ and charge a cartel price $p^{c}$. Under such a cartel regime, total welfare is given by the area $a h p^{c}+p^{c} h g c-$ $c g i=a c g h-c g i=a b c-b h i$. Observe that in this particular example a profitmaximizing cartel would lead to a less than optimal welfare standard. However, as $a b c-b h i>a b c-b d e$, total welfare is higher with this cartel contract than with competition. In fact, it is easy to see that bhi $<$ bde as long as $Q^{*}>Q^{c}>Q^{s}$. Consequently, if there are negative externalities in production, a hard core cartel is welfare-enhancing when total cartel production is lower than in competition, but exceeds socially optimal output levels.

\footnotetext{
${ }^{19}$ Note that the marginal damages of production in this particular example are significant as total welfare would be higher with zero industry output.
} 


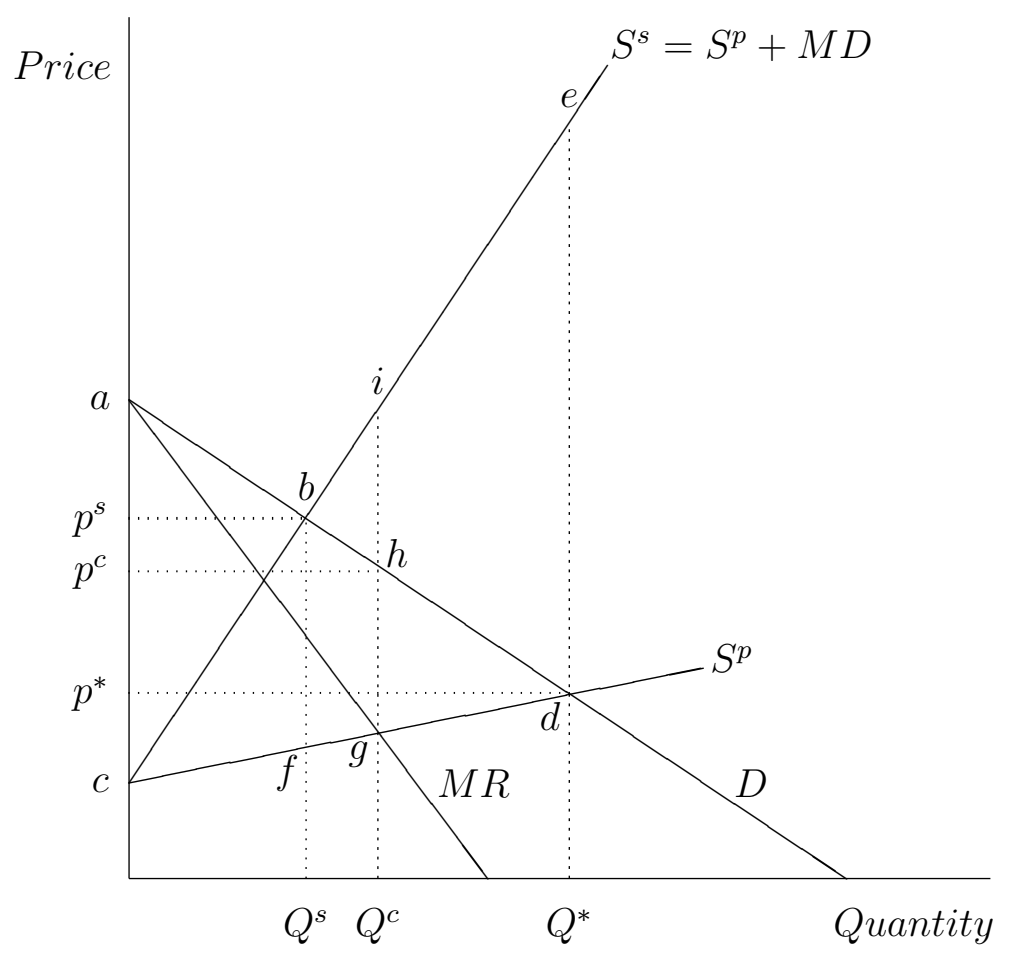

Figure 1: Welfare-Enhancing Cartel with $Q^{*}>Q^{c}>Q^{s}$.

Yet, a hard core cartel can be welfare-enhancing even when it reduces industry output below the socially optimal production level. This possibility is depicted in Figure 2.

As with the situation sketched in Figure 1, total welfare in competition is marked by the area $a b c-b d e$ and total surplus corresponding to the socially optimal pricequantity combination is given by the triangle $a b c$. In Figure 2, a profit-maximizing cartel will reduce industry output to $Q^{c}$, which is less than $Q^{s}$. Welfare under a cartel regime is then given by $a h p^{c}+p^{c} c g h-c g i=a c g h-c g i=$ ahic. Observe that the area $a h i c$ equals $a b c-h i b$. Thus, total surplus with a cartel regime is higher than in competition as long as $a b c-h i b>a b c-b d e$ or $b d e>h i b$, which is the case in Figure 2. Hence, in markets that exhibit negative externalities, a hard core cartel can be welfare-enhancing when total cartel production is below the welfare-maximizing output level.

In sum, a naked hard core cartel can be welfare-enhancing in industries with severe negative externalities in production as long as industry output is not restricted 'too much'. Clearly, whether or not a cartel will actually lead to an increase in total surplus ultimately depends on the elasticity of supply and demand as well as on the magnitude of the negative externalities. 


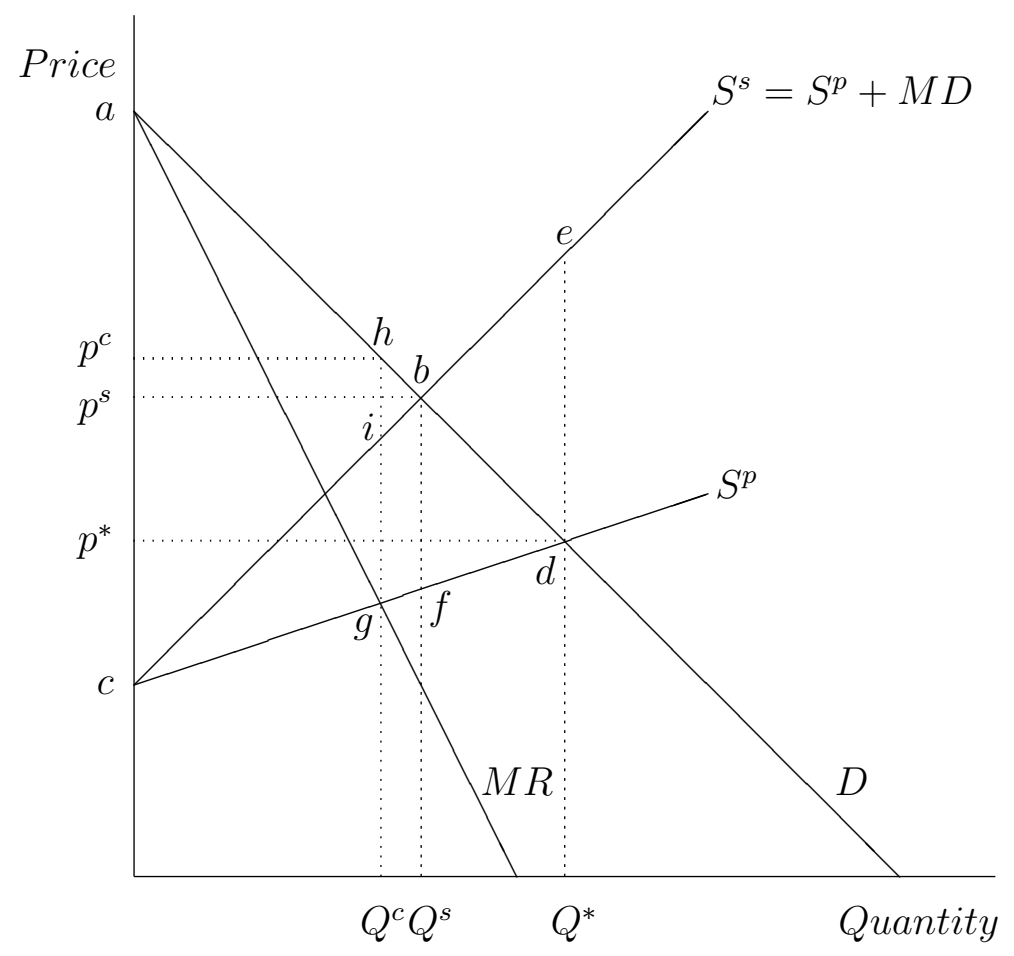

Figure 2: Welfare-Enhancing Cartel with $Q^{*}>Q^{s}>Q^{c}$.

\section{Appendix B: Proofs}

Proof of Lemma 5. Suppose $\pi_{i}^{\prime}\left(q_{i}^{*}\right) \geq 0$ for $i=1,2$ and suppose further that there exists a direction $\mathbf{u}=\left(u_{1}, u_{2}\right)$ for which Condition 3 and Condition $4(i)$ are satisfied. We will show that this yields a contradiction. We can distinguish two cases: $u_{1}>0$ and $u_{1} \leq 0$.

1. If $u_{1}>0$, then it must be the case that $u_{2}>0$, because otherwise Condition $4(i)$ is violated for firm 2 . However, $u_{1}>0$ and $u_{2}>0$ is not allowed as $u_{1}+u_{2}<0$ by assumption.

2. If $u_{1} \leq 0$, then it must be the case that $u_{2}<0$, because otherwise Condition $4(i)$ is violated for firm 1 . This implies $u_{1}<0$, because otherwise Condition $4(i)$ is violated for firm 2. For Condition 3 to hold with $u_{1}<0$ and $u_{2}<0$, we then need that $p^{*}-C_{2}^{\prime}\left(q_{2}^{*}\right)<0$ as $C_{1}^{\prime}\left(q_{1}^{*}\right) \leq C_{2}^{\prime}\left(q_{2}^{*}\right)$ by Axiom 1. However, if $p^{*}-C_{2}^{\prime}\left(q_{2}^{*}\right)<0$, then $p^{*}-C_{2}^{\prime}\left(q_{2}^{*}\right)+p^{* \prime} q_{2}^{*}<0$, because $p^{* \prime} q_{2}^{*}<0$. Thus, $\pi_{2}^{\prime}\left(q_{2}^{*}\right)<0$, which yields a contradiction. 
Proof of Theorem 6. By Lemma 5, we know that a necessary condition for the existence of an individually rational welfare-enhancing weak cartel is that $\pi_{i}^{\prime}\left(q_{i}^{*}\right)<0$ for at least one firm $i$. What remains is to derive sufficient conditions for the existence of such a cartel. We can distinguish two cases: (1) $p^{*}-C_{i}^{\prime}\left(q_{i}^{*}\right)<0$, for at least one firm $i$, and $(2) p^{*}-C_{i}^{\prime}\left(q_{i}^{*}\right) \geq 0$, for $i=1,2$.

1. Suppose that $p^{*}-C_{i}^{\prime}\left(q_{i}^{*}\right)<0$, for at least one firm $i$. By Axiom 1 , we know that $C_{1}^{\prime}\left(q_{1}^{*}\right) \leq C_{2}^{\prime}\left(q_{2}^{*}\right)$, which implies $p^{*}-C_{2}^{\prime}\left(q_{2}^{*}\right)<0$. In this case, Conditions 3 and $4(i)$ can be satisfied simultaneously with, for instance, $u_{1}=0$ and $u_{2}<0$.

2. Suppose that $p^{*}-C_{i}^{\prime}\left(q_{i}^{*}\right) \geq 0$, for $i=1,2$. By Axiom 1, it follows that $p^{*}-$ $C_{1}^{\prime}\left(q_{1}^{*}\right) \geq p^{*}-C_{2}^{\prime}\left(q_{2}^{*}\right) \geq 0$. In order for Condition 3 to hold, we thus need that $u_{1}>0$ and $u_{2}<0$ with $\left|u_{2}\right|>u_{1}$. More specifically, for the cartel to be welfare-enhancing, it is required that

$$
u_{2}>-u_{1} \frac{p^{*}-C_{1}^{\prime}\left(q_{1}^{*}\right)}{p^{*}-C_{2}^{\prime}\left(q_{2}^{*}\right)}
$$

with $u_{1}>0$ and $u_{2}<0$. Following Condition $4(i)$, firm 1 find it in its interest to take part in the cartel when

$$
u_{1}\left(p^{*}-C_{1}^{\prime}\left(q_{1}^{*}\right)\right)+\left(u_{1}+u_{2}\right) p^{* \prime} q_{1}^{*}>0 \text { with } u_{1}+u_{2}<0 .
$$

Hence, Condition $4(i)$ is satisfied for firm 1 , because $p^{* \prime} q_{1}^{*}<0, u_{1}>0$ and $p^{*}-C_{1}^{\prime}\left(q_{1}^{*}\right)>0$. Notice that, for Condition $4(i)$ to hold for firm 2 , it is required that $\pi_{2}^{\prime}\left(q_{2}^{*}\right)<0$ and

$$
u_{2}<-u_{1} \frac{p^{* \prime} q_{2}^{*}}{p^{*}-C_{2}^{\prime}\left(q_{2}^{*}\right)+p^{* \prime} q_{2}^{*}} .
$$

Combining (10) with (11) then defines an interval of values for $u_{2}$ for which the cartel is individually rational and welfare-enhancing:

$$
-u_{1} \frac{p^{*}-C_{1}^{\prime}\left(q_{1}^{*}\right)}{p^{*}-C_{2}^{\prime}\left(q_{2}^{*}\right)}<u_{2}<-u_{1} \frac{p^{* \prime} q_{2}^{*}}{p^{*}-C_{2}^{\prime}\left(q_{2}^{*}\right)+p^{* \prime} q_{2}^{*}} .
$$

Thus, there exists a value $u_{2}$ for which (10) and (11) hold simultaneously when

$$
\frac{p^{*}-C_{1}^{\prime}\left(q_{1}^{*}\right)}{p^{*}-C_{2}^{\prime}\left(q_{2}^{*}\right)}>\frac{p^{* \prime} q_{2}^{*}}{p^{*}-C_{2}^{\prime}\left(q_{2}^{*}\right)+p^{* \prime} q_{2}^{*}}
$$

Rearranging yields,

$$
p^{*}-C_{2}^{\prime}\left(q_{2}^{*}\right)<\frac{p^{* \prime} q_{2}^{*}\left(p^{*}-C_{1}^{\prime}\left(q_{1}^{*}\right)\right)}{p^{* \prime} q_{2}^{*}-\left(p^{*}-C_{1}^{\prime}\left(q_{1}^{*}\right)\right)}
$$


Notice that, in light of case 1 above, (12) is effective only when the right hand side of (12) is positive. If this is the case, then $\pi_{2}^{\prime}\left(q_{2}^{*}\right)<0$. To see this, add $p^{* \prime} q_{2}^{*}$ to both sides of (12), which yields

$$
p^{*}-C_{2}^{\prime}\left(q_{2}^{*}\right)+p^{* \prime} q_{2}^{*}<\frac{p^{* \prime} q_{2}^{*}\left(p^{*}-C_{1}^{\prime}\left(q_{1}^{*}\right)\right)}{p^{* \prime} q_{2}^{*}-\left(p^{*}-C_{1}^{\prime}\left(q_{1}^{*}\right)\right)}+p^{* \prime} q_{2}^{*},
$$

which is equivalent to

$$
\pi_{2}^{\prime}\left(q_{2}^{*}\right)<p^{* \prime} q_{2}^{*}\left(\frac{p^{* \prime} q_{2}^{*}}{p^{* \prime} q_{2}^{*}-\left(p^{*}-C_{1}^{\prime}\left(q_{1}^{*}\right)\right)}\right) .
$$

The right hand side of (13) is negative. Hence, $\pi_{2}^{\prime}\left(q_{2}^{*}\right)<0$ and the requirement of Lemma 5 is met.

Proof of Corollary 7. Suppose that $p^{*}-C_{2}^{\prime}\left(q_{2}^{*}\right) \geq 0$. Following Theorem 6 , an individually rational welfare-enhancing weak cartel exists if and only if

$$
p^{*}-C_{2}^{\prime}\left(q_{2}^{*}\right)<\frac{p^{* \prime} q_{2}^{*}\left(p^{*}-C_{1}^{\prime}\left(q_{1}^{*}\right)\right)}{p^{* \prime} q_{2}^{*}-\left(p^{*}-C_{1}^{\prime}\left(q_{1}^{*}\right)\right)} .
$$

Multiplying the numerator and denominator at the right hand side of (14) with $-\frac{Q^{*}}{Q^{*} p^{*}}$ yields

$$
p^{*}-C_{2}^{\prime}\left(q_{2}^{*}\right)<\frac{s_{2}}{s_{2}+\varepsilon\left(\frac{p^{*}-C_{1}^{\prime}\left(q_{1}^{*}\right)}{p^{*}}\right)}\left(p^{*}-C_{1}^{\prime}\left(q_{1}^{*}\right)\right),
$$

where $\varepsilon \equiv-\frac{\partial Q}{\partial p} \frac{p^{*}}{Q^{*}}$ and $s_{2}=\frac{q_{2}^{*}}{Q^{*}}$. Rearranging this term yields

$$
s_{2}\left(p^{*}-C_{2}^{\prime}\left(q_{2}^{*}\right)\right)+\varepsilon\left(\frac{p^{*}-C_{1}^{\prime}\left(q_{1}^{*}\right)}{p^{*}}\right)\left(p^{*}-C_{2}^{\prime}\left(q_{2}^{*}\right)\right)<s_{2}\left(p^{*}-C_{1}^{\prime}\left(q_{1}^{*}\right)\right),
$$

which is equivalent to

$$
p^{*}-C_{2}^{\prime}\left(q_{2}^{*}\right)<\frac{s_{2}}{\varepsilon\left(\frac{p^{*}-C_{1}^{\prime}\left(q_{1}^{*}\right)}{p^{*}}\right)}\left(C_{2}^{\prime}\left(q_{2}^{*}\right)-C_{1}^{\prime}\left(q_{1}^{*}\right)\right) .
$$

Proof of Lemma 8. Consider Condition 4(ii):

$$
u_{1}\left(p^{*}-C_{1}^{\prime}\left(q_{1}^{*}\right)\right)+u_{2}\left(p^{*}-C_{2}^{\prime}\left(q_{2}^{*}\right)\right)+\left(u_{1}+u_{2}\right) p^{* \prime} Q^{*}>0 \text { with } u_{1}+u_{2}<0 .
$$

As $u_{1}+u_{2}<0$, we know that $\left(u_{1}+u_{2}\right) p^{* \prime} Q^{*}>0$ at all $Q^{*}>0$. Hence, Condition 4 (ii) holds whenever

$$
u_{1}\left(p^{*}-C_{1}^{\prime}\left(q_{1}^{*}\right)\right)+u_{2}\left(p^{*}-C_{2}^{\prime}\left(q_{2}^{*}\right)\right)>0,
$$


which is Condition 3. Therefore, whenever Condition 3 is satisfied, Condition $4($ ii $)$ is satisfied too.

Proof of Theorem 9. First notice that by Lemma 8 it is sufficient to focus exclusively on Condition 3.

- Part $(i)$ : Suppose $C_{1}^{\prime}\left(q_{1}^{*}\right)<C_{2}^{\prime}\left(q_{2}^{*}\right)$ and therefore $p^{*}-C_{1}^{\prime}\left(q_{1}^{*}\right)>p^{*}-C_{2}^{\prime}\left(q_{2}^{*}\right)$. Now consider the direction $\mathbf{u}=\left(u_{1}, u_{2}\right)$ with $u_{1}>0$ and $u_{2}<-u_{1}$ (so that $\left.u_{1}+u_{2}<0\right)$. We can distinguish three cases:

1. $p^{*}-C_{1}^{\prime}\left(q_{1}^{*}\right)=0$ or $p^{*}-C_{2}^{\prime}\left(q_{2}^{*}\right)=0$. It follows immediately that Condition 3 is satisfied.

2. $p^{*}-C_{1}^{\prime}\left(q_{1}^{*}\right)>0$. In this case, Condition 3 holds whenever there exists a direction $\mathbf{u}$ such that

$$
\frac{u_{1}}{-u_{2}}>\frac{p^{*}-C_{2}^{\prime}\left(q_{2}^{*}\right)}{p^{*}-C_{1}^{\prime}\left(q_{1}^{*}\right)}
$$

As $\frac{u_{1}}{-u_{2}} \in(0,1),(15)$ always holds for $p^{*}-C_{2}^{\prime}\left(q_{2}^{*}\right) \leq 0$. If $p^{*}-C_{2}^{\prime}\left(q_{2}^{*}\right)>0$, then

$$
0<\frac{p^{*}-C_{2}^{\prime}\left(q_{2}^{*}\right)}{p^{*}-C_{1}^{\prime}\left(q_{1}^{*}\right)}<1 .
$$

Notice that, as $\frac{u_{1}}{-u_{2}} \in(0,1)$, there always exist values for $u_{1}$ and $u_{2}$ such that

$$
1>\frac{u_{1}}{-u_{2}}>\frac{p^{*}-C_{2}^{\prime}\left(q_{2}^{*}\right)}{p^{*}-C_{1}^{\prime}\left(q_{1}^{*}\right)}>0 .
$$

3. $p^{*}-C_{1}^{\prime}\left(q_{1}^{*}\right)<0$. In this case, Condition 3 holds whenever there exists a direction $\mathbf{u}$ such that

$$
\frac{u_{1}}{-u_{2}}<\frac{p^{*}-C_{2}^{\prime}\left(q_{2}^{*}\right)}{p^{*}-C_{1}^{\prime}\left(q_{1}^{*}\right)}
$$

As $\frac{p^{*}-C_{2}^{\prime}\left(q_{2}^{*}\right)}{p^{*}-C_{1}^{\prime}\left(q_{1}^{*}\right)}>1$ and $\frac{u_{1}}{-u_{2}} \in(0,1),(16)$ always holds.

- Part (ii): Suppose $C_{1}^{\prime}\left(q_{1}^{*}\right)=C_{2}^{\prime}\left(q_{2}^{*}\right)=C$. In this case, Condition 3 simplifies to $\left(u_{1}+u_{2}\right)\left(p^{*}-C\right)>0$. As $u_{1}+u_{2}<0$, Condition 3 can only be satisfied when $p^{*}<C$.

\section{Proof of Proposition 10.}

- Part $(i)$ : Suppose that $C_{i}^{\prime}(\cdot)>0$ and $C_{i}^{\prime \prime}(\cdot)=0$, for $i=1,2$. Following Axiom 1 , we need that $C_{1}^{\prime}(\cdot)=C_{2}^{\prime}(\cdot)$, because otherwise $q_{2}^{*}=0$ (as firm 1 would optimally set a price slightly below the marginal production costs of firm 2). 
With $C_{1}^{\prime}(\cdot)=C_{2}^{\prime}(\cdot)$, there are two (symmetric) Nash equilibria: $p^{*}=C_{i}^{\prime}\left(\frac{1}{2} Q^{*}\right)$ and $p^{*}=C_{i}^{\prime}\left(\frac{1}{2} Q^{*}\right)+\varepsilon$, which coincide as $\varepsilon \downarrow 0$.

By Theorem 6, we know that Conditions 3 and $4(i)$ can be satisfied simultaneously if and only if

$$
p^{*}-C_{2}^{\prime}\left(q_{2}^{*}\right)<\max \left\{0, \frac{p^{* \prime} q_{2}^{*}\left(p^{*}-C_{1}^{\prime}\left(q_{1}^{*}\right)\right)}{p^{* \prime} q_{2}^{*}-\left(p^{*}-C_{1}^{\prime}\left(q_{1}^{*}\right)\right)}\right\} .
$$

As $p^{*}-C_{2}^{\prime}\left(q_{2}^{*}\right)=0$, we must have that

$$
\frac{p^{* \prime} q_{2}^{*}\left(p^{*}-C_{1}^{\prime}\left(q_{1}^{*}\right)\right)}{p^{* \prime} q_{2}^{*}-\left(p^{*}-C_{1}^{\prime}\left(q_{1}^{*}\right)\right)}>0
$$

which implies $p^{*}-C_{1}^{\prime}\left(q_{1}^{*}\right)>0$. Consequently, $C_{1}^{\prime}\left(q_{1}^{*}\right)<C_{2}^{\prime}\left(q_{2}^{*}\right)$, which yields a contradiction. Thus, if both firms have constant unit production costs, then there exists no welfare-enhancing weak cartel.

- Part $(i i)$ : Suppose that $C_{i}^{\prime}(\cdot)>0$ and $C_{i}^{\prime \prime}(\cdot)>0$, for $i=1,2$. We will show that there exists a $p^{*}$ such that $p^{*}<C_{i}^{\prime}\left(q_{i}^{*}\right)$ for at least one firm $i$, which in light of Theorem 6 is sufficient for the existence of a welfare-enhancing weak cartel.

First note that Axiom 1 implies that both firms set the same price in equilibrium. Furthermore, a firm can always guarantee itself zero profits by raising its price above the price set by its rival. Hence, any $p^{*}$ must satisfy

$$
p^{*} q_{i}^{*}-C_{i}\left(q_{i}^{*}\right) \geq 0, \text { for } i=1,2 .
$$

As $q_{i}^{*}=\frac{1}{2} Q\left(p^{*}\right)$, for $i=1,2$, this is equivalent to

$$
p^{*} \frac{1}{2} Q\left(p^{*}\right)-C_{i}\left(\frac{1}{2} Q\left(p^{*}\right)\right) \geq 0, \text { for } i=1,2 .
$$

Rearranging yields

$$
p^{*} \geq \frac{C_{i}\left(\frac{1}{2} Q\left(p^{*}\right)\right)}{\frac{1}{2} Q\left(p^{*}\right)}, \text { for } i=1,2 .
$$

Thus, in equilibrium, prices (weakly) exceed the average production costs for both firms.

In addition, at an equilibrium price $p^{*}$ none of the firms finds it profitable to undercut this price. Therefore, the following condition must be satisfied as well.

$$
p^{*} \frac{1}{2} Q\left(p^{*}\right)-C_{i}\left(\frac{1}{2} Q\left(p^{*}\right)\right) \geq p^{*} Q\left(p^{*}\right)-C_{i}\left(Q\left(p^{*}\right)\right), \text { for } i=1,2,
$$


where the right-hand side of (18) is (approximately) the profit that can be obtained by slightly undercutting $p^{*}$. Rearranging (18) gives

$$
p^{*} \leq \frac{C_{i}\left(Q\left(p^{*}\right)\right)-C_{i}\left(\frac{1}{2} Q\left(p^{*}\right)\right)}{\frac{1}{2} Q\left(p^{*}\right)}, \text { for } i=1,2 .
$$

Thus, in equilibrium, prices are weakly lower than the average costs of the additional production that can be obtained by undercutting $p^{*}$.

Combining (17) with (19) then defines a set of equilibrium prices, which is denoted by $\mathcal{P}$. Formally,

$$
p^{*} \in \mathcal{P} \mid \frac{C_{i}\left(\frac{1}{2} Q\left(p^{*}\right)\right)}{\frac{1}{2} Q\left(p^{*}\right)} \leq p^{*} \leq \frac{C_{i}\left(Q\left(p^{*}\right)\right)-C_{i}\left(\frac{1}{2} Q\left(p^{*}\right)\right)}{\frac{1}{2} Q\left(p^{*}\right)}, \text { for } i=1,2 .
$$

Notice that for such a $p^{*}$ to exist it is necessary that $C_{i}\left(Q\left(p^{*}\right)\right) \geq 2 C_{i}\left(\frac{1}{2} Q\left(p^{*}\right)\right)$, for $i=1,2$, which is the case as $C_{i}^{\prime}(\cdot)>0$ and $C_{i}^{\prime \prime}(\cdot)>0$, for $i=1,2$, by assumption. Furthermore, note that Axiom 1 implies that $\mathcal{P}$ is non-empty. Finally, as $C_{i}^{\prime}(\cdot)>0$ and $C_{i}^{\prime \prime}(\cdot)>0$, for $i=1,2$, we also know that at any $p^{*}$,

$$
\frac{C_{i}\left(\frac{1}{2} Q\left(p^{*}\right)\right)}{\frac{1}{2} Q\left(p^{*}\right)}<C_{i}^{\prime}\left(\frac{1}{2} Q\left(p^{*}\right)\right)<\frac{C_{i}\left(Q\left(p^{*}\right)\right)-C_{i}\left(\frac{1}{2} Q\left(p^{*}\right)\right)}{\frac{1}{2} Q\left(p^{*}\right)}, \text { for } i=1,2 .
$$

In the following, we show that there is an element of $\mathcal{P}$ that is below unit costs of at least one firm. To that end, let $p_{i}^{\circ} \equiv \frac{C_{i}\left(\frac{1}{2} Q\left(p_{i}^{\circ}\right)\right)}{\frac{1}{2} Q\left(p_{i}^{\circ}\right)}$ and $p^{\circ} \equiv \max \left\{p_{1}^{\circ}\right.$, $\left.p_{2}^{\circ}\right\}$. If $p^{\circ} \in \mathcal{P}$, then it follows from $(21)$ that $p^{\circ}=\frac{C_{i}\left(\frac{1}{2} Q\left(p^{\circ}\right)\right)}{\frac{1}{2} Q\left(p^{\circ}\right)}<C_{i}^{\prime}\left(\frac{1}{2} Q\left(p^{\circ}\right)\right)$, which by Theorem 6 completes the proof.

Suppose $p^{\circ} \notin \mathcal{P}$. We will show that this yields a contradiction. Let $p^{\circ}=$ $\frac{C_{i}\left(\frac{1}{2} Q\left(p^{\circ}\right)\right)}{\frac{1}{2} Q\left(p^{\circ}\right)}$ for firm $i$ and $p^{\circ} \geq \frac{C_{j}\left(\frac{1}{2} Q\left(p^{\circ}\right)\right)}{\frac{1}{2} Q\left(p^{\circ}\right)}$ for firm $j$. By (21), we know that for firm $i, p^{\circ}=\frac{C_{i}\left(\frac{1}{2} Q\left(p^{\circ}\right)\right)}{\frac{1}{2} Q\left(p^{\circ}\right)}<C_{i}^{\prime}\left(\frac{1}{2} Q\left(p^{\circ}\right)\right)$. Hence, firm $i$ cannot increase profits by undercutting $p^{\circ}$, because the price-cost margin on any additional production would be negative. Moreover, it cannot increase profits by raising its price above $p^{\circ}$, because its current profits are 0 . At $p^{\circ}$, firm $j$ has a nonnegative profit and therefore it cannot increase profits by raising its price above $p^{\circ}$. The fact that $p^{\circ} \notin \mathcal{P}$ then implies that firm $j$ can profitably undercut $p^{\circ}$, i.e.,

$$
p^{\circ}>\frac{C_{j}\left(Q\left(p^{\circ}\right)\right)-C_{j}\left(\frac{1}{2} Q\left(p^{\circ}\right)\right)}{\frac{1}{2} Q\left(p^{\circ}\right)} .
$$

Recall that $\mathcal{P}$ is non-empty, which implies that there exist a price $p \in \mathcal{P}$ and $p \neq p^{\circ}$. This leaves two possibilities. (1) $\exists p \in \mathcal{P}$ such that $p<p^{\circ}$, which is 
impossible as this would give firm $i$ a negative profit. (2) $\exists p \in \mathcal{P}$ such that $p>p^{\circ}$, which implies

$$
\frac{C_{j}(Q(p))-C_{j}\left(\frac{1}{2} Q(p)\right)}{\frac{1}{2} Q(p)}<\frac{C_{j}\left(Q\left(p^{\circ}\right)\right)-C_{j}\left(\frac{1}{2} Q\left(p^{\circ}\right)\right)}{\frac{1}{2} Q\left(p^{\circ}\right)},
$$

because $C_{i}^{\prime}(\cdot)>0$ and $C_{i}^{\prime \prime}(\cdot)>0$, for $i=1,2$. As $p^{\circ}>\frac{C_{j}\left(Q\left(p^{\circ}\right)\right)-C_{j}\left(\frac{1}{2} Q\left(p^{\circ}\right)\right)}{\frac{1}{2} Q\left(p^{\circ}\right)}$, it follows that $p>\frac{C_{j}(Q(p))-C_{j}\left(\frac{1}{2} Q(p)\right)}{\frac{1}{2} Q(p)}$ for any $p>p^{\circ}$. Thus, there is always a possibility for firm $j$ to profitably undercut and therefore $p \notin \mathcal{P}$, which yields a contradiction. Hence, $p^{\circ} \in \mathcal{P}$.

\section{Proof of Proposition 11.}

- Part $(i)$ : Suppose that $C_{i}^{\prime}(\cdot)>0$ and $C_{i}^{\prime \prime}(\cdot)=0$, for $i=1,2$. Following Axiom 1 , we need that $C_{1}^{\prime}(\cdot)=C_{2}^{\prime}(\cdot)$, because otherwise $q_{2}^{*}=0$ (as firm 1 would optimally set a price slightly below the marginal production costs of firm 2). With $C_{1}^{\prime}(\cdot)=C_{2}^{\prime}(\cdot)$, there are two (symmetric) Nash equilibria: $p^{*}=C_{i}^{\prime}\left(\frac{1}{2} Q^{*}\right)$ and $p^{*}=C_{i}^{\prime}\left(\frac{1}{2} Q^{*}\right)+\varepsilon$, which coincide as $\varepsilon \downarrow 0$. By Theorem $9(i i)$, however, we know that for an individually rational welfare-enhancing strong cartel to exist it must be the case that $C_{1}^{\prime}\left(q_{1}^{*}\right)=C_{2}^{\prime}\left(q_{2}^{*}\right)>p^{*}$.

- Part (ii): See proof Proposition 10(ii).

Proof of Proposition 13. By Lemma 5, we know that a necessary condition for the existence of an individually rational welfare-enhancing weak cartel is that $\pi_{i}^{\prime}\left(q_{i}^{*}\right)<0$ for at least one firm $i$. In a Cournot Nash equilibrium, however, firms set their outputs such that $\pi_{i}^{\prime}\left(q_{i}^{*}\right)=0$, for $i=1,2$.

Proof of Proposition 14. In a Cournot Nash equilibrium, we either have that (1) $C_{1}^{\prime}\left(q_{1}^{*}\right)<C_{2}^{\prime}\left(q_{2}^{*}\right)$, or $(2) C_{1}^{\prime}\left(q_{1}^{*}\right)=C_{2}^{\prime}\left(q_{2}^{*}\right)$.

1. By Theorem $9(i)$, we know that Conditions 3 and $4(i i)$ can be satisfied simultaneously.

2. By Theorem $9(i i)$, we know that Conditions 3 and $4(i i)$ can be satisfied simultaneously only if $C_{1}^{\prime}\left(q_{1}^{*}\right)=C_{2}^{\prime}\left(q_{2}^{*}\right)>p^{*}$. In a Cournot Nash equilibrium it holds that $\pi_{i}^{\prime}\left(q_{i}\right)=p^{\prime}(Q) q_{i}+p(Q)-C_{i}^{\prime}\left(q_{i}\right)=0$, for $i=1,2$. Note that $p^{\prime}(Q) q_{i}<0$, which implies that $p^{*}>C_{i}^{\prime}\left(q_{i}^{*}\right)$, for $i=1,2$. Hence, Conditions 3 and $4(i i)$ cannot be satisfied simultaneously when $C_{1}^{\prime}\left(q_{1}^{*}\right)=C_{2}^{\prime}\left(q_{2}^{*}\right)$. 


\section{References}

[1] Bittlingmayer, George (1995), "Output and Stock Prices when Antitrust is Suspended: The Effects of the NIRA," in: McChesney, Fred S. and Shughart II, William F. (eds.), "The Causes and Consequences of Antitrust: The Public Choice Perspective," The University of Chicago Press, Chicago, 287-318;

[2] Bittlingmayer, George (1982), "Decreasing Average Cost and Competition: A New Look at the Addyston Pipe Case," Journal of Law and Economics, 25, 201-229;

[3] Bork, Robert H. (1993), "The Antitrust Paradox: A Policy at War with Itself," New York, NY: The Free Press;

[4] Deltas, George, Alberto Salvo and Helder Vasconcelos (2009), "WelfareEnhancing Collusion and Trade," Working Paper;

[5] Dewey, Donald (1979), "Information, Entry and Welfare: The Case for Collusion," American Economic Review, 69(4), 587-594;

[6] Dick, Andrew R. (1996), "When are Cartels Stable Contracts?," Journal of Law and Economics, 39, 241-283;

[7] Doyle, Chris and Martijn A. Han (2009), "Efficient Cartelization through Buyer Groups," ACLE Working Paper, No. 2009-03;

[8] Fershtman, Chaim and Ariel Pakes (2000), "A Dynamic Oligopoly with Collusion and Price Wars," RAND Journal of Economics, 31(2), 207-236;

[9] Genesove, David and Wallace P. Mullin (2001), "Rules, Communication, and Collusion: Narrative Evidence from the Sugar Institute Case," American Economic Review, 91(3), 379-398;

[10] Harrington, Joseph E. Jr. (2006), "How do Cartels Operate?," Foundations and Trends in Microeconomics, 2(1), 1-105;

[11] Kinghorn, Janice R. (1996), "Kartells and Cartel Theory: Evidence from Early Twentieth Century German Coal, Iron and Steel Industries," Essays in Economic and Business History, 14, 339-363;

[12] Matsui, Akihiko (1989), "Consumer-benefited Cartels under Strategic Capital Investment Competition," International Journal of Industrial Organization, 7, 451-470;

[13] Montero, Juan-Pablo and Juan I. Guzmán (2005), "Welfare-Enhancing Collusion in the Presence of a Competitive Fringe," MIT CEEPR Working Paper Series, No. 0511; 
[14] OECD report (1998), "Recommendation of the Council concerning Effective Action against Hard Core Cartels," OECD Recommendations $\&$ Best Practices;

[15] Pesendorfer, Martin (2000), "A Study of Collusion in First-Price Auctions," Review of Economic Studies, 67(3), 381-411;

[16] Posner, Richard A. (1975), "The Social Costs of Monopoly and Regulation," Journal of Political Economy, 83(4), 807-828;

[17] Röller, Lars-Hendrik and Frode Steen (2006), "On the Workings of a Cartel: Evidence from the Norwegian Cement Industry," American Economic Review, 96(1), 321-338;

[18] Rotemberg, Julio J. (1998), "Government-enforced Cartels, Output and Welfare," Harvard Business School Working Paper, No. 98-116;

[19] Sjostrom, William (1989), "Collusion in Ocean Shipping: A Test of Monopoly and Empty Core Models," Journal of Political Economy, 97 (5), 1160-1179;

[20] Sproul, Michael F. (1993), "Antitrust and Prices," Journal of Political Economy, 101(4), 741-754;

[21] Taylor, Jason E. (2002), "The Output Effects of Government Sponsored Cartels During the New Deal," Journal of Industrial Economics, 50(1), 1-10;

[22] Telser, Lester G. (1996), "Competition and the Core," Journal of Political Economy, 104 (1), 85-107;

[23] Troesken, Werner (1989), "A Note on the Efficacy of the German Steel and Coal Syndicates," Explorations in Economic History, 18, 595-600;

[24] Williamson, Oliver E. (1968), "Economies as an Antitrust Defense: The Welfare Tradeoffs," American Economic Review, 58(1), 18-36; 